\title{
TENDÊNCIAS DE PESQUISAS RELACIONADAS À TEORIA HISTÓRICO-CULTURAL NOS ENCONTROS NACIONAIS DE PESQUISA EM EDUCAÇÃO E CIÊNCIAS DE 2013, 2015 E 2017
}

\author{
Hércules Ferrari Domingues da Silva ${ }^{1}$ \\ Carmem Lúcia Costa Amaral ${ }^{2}$
}

\begin{abstract}
RESUMO
Este trabalho descreve o resultado de um mapeamento dos trabalhos apresentados nos Encontros Nacionais de Pesquisa em Educação em Ciências IX, X e XI, cujo objetivo foi analisar os que abordaram os conceitos da Teoria Histórico-Cultural (THC) de Vygotsky e suas contribuições para o seu entendimento, bem como identificar as fontes bibliográficas utilizadas, as regiões que apresentaram trabalhos, quantidade de autores por trabalho e organizá-los em focos e subfocos temáticos. Foram selecionados 51 trabalhos, com destaque para as regiões Sudeste e Nordeste, com 58\% deste total, dos quais 68\% foram elaborados por 2 ou 3 pesquisadores. Nos aspectos relacionados à abordagem da THC os conceitos mais utilizados foram a Mediação e Linguagem, as obras mais citadas foram a Formação Social da Mente e Pensamento e Linguagem.
\end{abstract}

Palavras-chave: Mapeamento. Teoria histórico-cultural. Focos e subfocos temáticos.

\section{TRENDS OF RESEARCH RELATED TO THE HISTORICAL-CULTURAL THEORY IN THE NATIONAL} ENCOUNTERS OF RESEARCH IN EDUCATION AND SCIENCES OF 2013, 2015 AND 2017

\begin{abstract}
This research describes the results of a mapping of the works presented at the National Encounters of Education Research in Sciences IX, X and XI, whose objective was to analyze the articles that addressed the concepts of Vygotsky's Historical-Cultural Theory (THC) and its contributions to as well as to identify the bibliographic sources used, the regions that presented papers, the number of authors per article, and organize the articles in Focus and Thematic Subfocus. A total of 51 papers were selected, highlighting the Southeast and Northeast regions, with $58 \%$ of the papers presented. Of these, $68 \%$ were constructed by 2 or 3 researchers. In the aspects related to the THC approach, the most used concepts were Mediation and Language, the most cited works were the Social Formation of the Mind and Thought and Language.
\end{abstract}

Keywords: Mapping. Historical-cultural theory. Focus and theme subfocus.

RECEBIDO EM: 2/10/2018

ACEITO EM: 13/12/2018

\footnotetext{
${ }^{1}$ Mestrado em Educação (Educação Superior) e doutorando em Ensino de Ciências - Universidade Cruzeiro do Sul. herculesdomingues@hotmail.com

${ }^{2}$ Graduação em Química pela Universidade Federal do Rio Grande do Norte (1984), Mestrado em Química Orgânica (1988) e Doutorado em Química Orgânica (1993) pela Universidade de São Paulo. Professora titular III da Universidade Cruzeiro do Sul, coordenadora do curso EaD em Ensino de Química, vice-coordenadora do Programa de Pós-Graduação Stricto Sensu em Ensino de Ciências e Matemática e vice-coordenadora do Comitê de Ética em Pesquisa com seres humanos da Faculdade de Odontologia da Associação Paulista de Cirurgiões Dentistas. É professora pesquisadora do Programa de Mestrado e Doutorado em Ensino de Ciências e Ensino de Ciências e Matemática da Universidade Cruzeiro do Sul, atuando principalmente nos seguintes temas: ensino-aprendizagem de Química, relação Ciência Tecnologia e Sociedade no ensino de Química, temas transversais, ambiente virtual e jogos pedagógicos no ensino de Química. carmem.amaral@cruzeirodosul.edu.br
} 
Este artigo foi escrito com a finalidade de identificar nos Encontros Nacionais de Pesquisa em Educação em Ciências - Enpec IX (2013), X (2015) e XI (2017) os trabalhos que apresentam pesquisas de ensino de ciências relacionadas aos estudos realizados por Lev Semienovich Vygotsky, Alexis Nikolaevich Leontiev e Alexander Romanovich Luria, estudiosos russos que elaboraram a Teoria Histórico-Cultural (THC) na década de 20 e início da década de 30 do século 20, que tem como base o materialismo histórico-dialético, teoria utilizada pela antiga União das Repúblicas Socialistas Soviéticas - URSS - logo após a revolução bolchevista de 1917 (REGO, 2013).

Os Enpecs tiveram sua primeira edição em novembro de 1997, na cidade de Águas de Lindoia/SP, momento em que surgiu a iniciativa de criar a Associação Brasileira de Pesquisa em Educação em Ciências - Abrapec - a qual iniciou suas atividades no II Enpec, realizado em 1999, entidade que passou a organizar os encontros a partir de então e a publicar a Revista Brasileira de Pesquisa em Educação em Ciências - RBPEC além do que promove cursos e palestras na área (ABRAPEC, 2017).

A pesquisa concentrou-se em atender seu principal objetivo, o de mapear os trabalhos publicados nos eventos anteriormente citados, que utilizaram em seus textos aspectos relacionados à THC. Por outro lado, buscando organizar as informações e destacar a relevância nacional do referido evento, também foram consultados os Anais de todos os Enpecs desde o primeiro que foi realizado em 1997 (evento bianual) e que contou com 137 pesquisadores participantes e apresentação de 57 trabalhos, números que dobraram a cada edição, culminando com o VIII Enpec 2011, realizado na Unicamp, que contou com 1.920 pesquisadores e a apresentação de 1.235 trabalhos, média esta mantida no X e XI Enpec, mostrando-se evidente a evolução dos encontros e a sua importância no âmbito da Educação em Ciências no cenário brasileiro.

A fim de identificar e entender cada conceito da THC utilizado pelos autores dos trabalhos publicados nos Enpec IX, X e XI, bem como os aspectos discutidos e a correção dos conceitos apresentados, lançou-se mão do conhecimento construído com a leitura dos livros "Formação Social da Mente" (VYGOTSKY, 1991) e "Vygotsky: uma perspectiva histórico-cultural da educação" (REGO, 2013), "A construção do pensamento e da linguagem" (VYGOTSKY, 2009), "Pensamento e linguagem" (VYGOTSKY, 2008), "Linguagem, desenvolvimento e aprendizagem" (VYGOTSKY, 2017), "Psicologia pedagógica" (VYGOTSKY, 2010), como referenciais comparativos.

Desse modo, ao longo da análise dos trabalhos selecionados e definição de seus focos e subfocos temáticos, buscou-se analisar as abordagens relacionadas à THC destacadas pelos autores, enfatizando suas convergências e divergências de acordo com Fiorentini (2002).

Para melhor entendimento do conhecimento gerado por esta pesquisa os 51 trabalhos selecionados foram divididos em 6 focos temáticos, porém neste trabalho optou-se por apresentar apenas o Foco Temático Ensino de Ciências e seus Subfocos Temáticos, deixando os outros 5 para uma análise posterior, quando da continuidade dos trabalhos relacionados a esta pesquisa. 


\section{METODOLOGIA}

A pesquisa foi direcionada para a análise dos trabalhos publicados nos Anais dos Enpecs IX, X e XI, dos anos de 2013, 2015 e 2017, respectivamente, caracterizando-se como uma pesquisa bibliográfica, pois tais trabalhos para serem construídos receberam um tratamento analítico e são frutos de um estudo criterioso sobre a THC. Conforme explica Pradanov (2013, p. 54), uma pesquisa é definida como bibliográfica

quando elaborada a partir de material já publicado, constituído principalmente de: livros, revistas, publicações em periódicos e artigos científicos, jornais, boletins, monografias, dissertações, teses, material cartográfico, Internet, com o objetivo de colocar o pesquisador em contato direto com todo o material já escrito sobre o assunto da pesquisa.

O caráter qualitativo da pesquisa evidencia-se porque os dados das publicações serão analisados à luz da THC e seus preceitos fundamentais, buscando-se entender a subjetividade dos trabalhos analisados, como afirma Bogdan (1994, p. 48):

Na sua busca de conhecimento, os investigadores qualitativos não reduzem as muitas páginas contendo narrativas e outros dados a símbolos. Tentam analisar os dados em toda a sua riqueza, respeitando, tanto quanto o possível, a forma em que estes foram registados ou transcritos.

Na pesquisa junto aos sites dos Anais dos Enpecs 2013, 2015 e 2017, foram digitados descritores que remetiam à THC, utilizando-se as seguintes palavras-chave: Vigotski, Vygotsky, Vygotski, Histórico-cultural, Histórico-crítica, Mediação, Materialismo histórico-dialético, Sociocultural, Teoria crítica, Sociointeracionismo e Sócio-histórica. Também foram utilizados os outros ícones de busca existentes nos sites dos Anais dos Enpecs, buscando-se nos títulos, palavras-chave e bibliografias alguma informação que remetesse à Teoria Histórico-Cultural, sendo possível selecionar 51 trabalhos.

Quanto à leitura exploratória dos trabalhos, optou-se no primeiro momento por analisar os resumos de cada um, sendo possível extrair as informações para determinar os focos temáticos e os subfocos temáticos de aproximadamente $50 \%$ do total de 51 publicações selecionadas. Os outros $50 \%$ foram retirados do corpo do texto de cada trabalho, por meio de uma leitura flutuante e com a utilização do ícone de busca do processador de texto, utilizando palavras-chave.

A estrutura desta pesquisa tem como base teórica o que foi proposto por Fiorentini (2002) no artigo "Mapeamento e balanço dos trabalhos do GT-19 (Educação Matemática) no período de 1998 a 2001", tanto na organização do texto como na composição das tabelas e quadros.

$\mathrm{Na}$ apresentação dos primeiros resultados desta pesquisa são discutidos aspectos relacionados às origens das publicações, em seguida os trabalhos estão organizados em focos temáticos e subfocos temáticos. 


\section{APRESENTAÇÃO DE TRABALHOS POR REGIÃO, I ES E AUTORES DOS ENPECS IX - X - XI}

Nesta sessão buscar-se-á mapear os 51 trabalhos selecionados para este estudo respondendo às questões: Quais são as regiões que mais apresentaram trabalhos? Dentro destas regiões, quais os Estados que se destacaram? Quais as universidades que se destacaram? Quais os autores que são mais frequentes nas três edições?

Com a finalidade de entender melhor a relação quantidade de trabalhos que são inscritos e apresentados nos encontros, elaborou-se a Tabela 1, na qual é possível observar que aproximadamente $70 \%$ dos trabalhos submetidos são aceitos.

Tabela 1 - Comparativo de trabalhos inscritos e aceitos Enpecs

\begin{tabular}{l|c|c|c}
\hline INFORMAÇÕES & IX ENPEC - 2013 & X ENPEC- 2015 & XI ENPEC- 2017 \\
\hline Pesquisadores inscritos & 1.037 & 1476 & 1474 \\
\hline Submissão de trabalhos & 1.526 & 1728 & 1840 \\
\hline Trabalhos recusados & 466 & 496 & 505 \\
\hline Trabalhos aceitos & 1.019 & 1272 & 1335 \\
\hline
\end{tabular}

Fonte: Dados extraídos dos Anais do IX, X e XI Enpec.

Pesquisadores de todas as regiões do Brasil apresentaram trabalhos nos Enpecs de 2013, 2015 e 2017, demonstrando a abrangência nacional do evento, sendo 37,25\% da região Sudeste, $21,57 \%$ do Nordeste, $19,61 \%$ do Sul, $13,73 \%$ do Centro-Oeste, 3,92\% do Norte e 3,92\% não consta a região, porém apenas pesquisadores de 13 Estados apresentaram trabalhos, dos quais 74,5\% do total têm sua origem em apenas 6 Estados: São Paulo, Bahia, Rio Grande do Sul, Espírito Santo, Paraná e Mato Grosso do Sul.

A IES que teve o maior número de trabalhos aprovados foi a Universidade Federal da Bahia, com 9 pesquisadores presentes, com a peculiaridade de que 7 destes trabaIhos abordaram a "Pedagogia Histórico-Crítica-PHC", cujas origens estão na THC. No Estado de São Paulo apenas a Universidade de São Paulo e a Universidade Estadual Paulista tiveram trabalhos apresentados, totalizando 4 e 5 , respectivamente.

Como a autoria também está relacionada às origens dos trabalhos, lançou-se luz sobre este aspecto, sendo observado durante a análise do fichamento dos dados que apenas 6 trabalhos foram escritos por 1 autor, 22 por 2 autores, 13 por 3 autores, 4 por 4 autores, 3 por 5 autores, 1 por 6 autores, e em 2 não foi possível identificar a autoria.

\section{FOCOS TEMÁTICOS E SUBFOCOS TEMÁTICOS DOS ENPECS IX, X E XI}

Segundo Fiorentini (2002, p. 4), a organização temática de um mapeamento propõe que seja definido o "foco principal da investigação. Este processo não é simples ou direto, pois acontece de forma indutiva e, às vezes, dedutiva, exigindo ajustes individuais (para cada aluno) e grupais (envolvendo um conjunto de estudos)". 
Esta forma de organizar a pesquisa permite algumas vantagens para o entendimento do que se busca encontrar, como afirma Fiorentini (2002, p. 4-5):

A vantagem é que as categorias construídas emergem do material sob análise e não da literatura propriamente dita, embora, neste processo, o diálogo com a literatura e outras formas de classificação seja conveniente e necessário. 0 resultado obtido, isto é, o quadro dos estudos organizados tematicamente, é uma elaboração particular relativa àquele conjunto de trabalhos, não sendo, portanto, facilmente transferível para outros conjuntos. A vantagem dessa forma de organização é que ela permite comparar por contraste os diferentes olhares e resultados produzidos, independendo da opção teórica ou metodológica de cada estudo. Isso não significa ecletismo. Significa, acima e tudo, respeito à diversidade e às múltiplas formas de produzir conhecimentos dentro de um campo específico como o da Educação Matemática.

Nesta pesquisa os trabalhos foram divididos em 6 focos temáticos e 23 subfocos (Quadro 1), ressaltando-se que durante as descrições buscou-se os pontos de convergências dos subfocos dentro do foco temático.

Quadro 1 - Focos temáticos e subfocos temáticos dos trabalhos selecionados

\begin{tabular}{|c|c|c|c|}
\hline $\begin{array}{l}\text { FOCO } \\
\text { TEMÁTICO }\end{array}$ & № & SUBFOCO & TRABALHOS* \\
\hline \multirow{9}{*}{$\begin{array}{l}\text { Ensino de } \\
\text { Ciências }\end{array}$} & \multirow{9}{*}{23} & Ensino Fundamental, mediação, pensamento crítico & $\begin{array}{l}\text { A6, A32, } \\
\text { A41 e A42 }\end{array}$ \\
\hline & & $\begin{array}{l}\text { Ensino Médio, abordagem de contexto, questões históricas } \\
\text { e socioculturais, Pedagogia histórico-crítica }\end{array}$ & $\begin{array}{l}\text { A7, A35 e } \\
\text { A49 }\end{array}$ \\
\hline & & $\begin{array}{l}\text { Mediação, sociocultural, análise crítica, interações, } \\
\text { internalização }\end{array}$ & $\begin{array}{l}\text { A9, A12 e } \\
\text { A14 }\end{array}$ \\
\hline & & $\begin{array}{l}\text { Mapeamento, Pedagogia Histórico-Crítica, teoria histórico- } \\
\text { cultural }\end{array}$ & $\begin{array}{l}\text { A17, A43, } \\
\text { A46 e A51 }\end{array}$ \\
\hline & & $\begin{array}{l}\text { Conceito espontâneo e científico, experimentação, teoria } \\
\text { histórico-cultural }\end{array}$ & $\begin{array}{l}\text { A } 18, \text { A20 e } \\
\text { A38 }\end{array}$ \\
\hline & & $\begin{array}{l}\text { Ensino Fundamental, uso de tecnologia, mediação, } \\
\text { internalização, teoria histórico-cultural }\end{array}$ & $\begin{array}{l}\text { A25, A26 e } \\
\text { A29 }\end{array}$ \\
\hline & & Teoria da ação mediada, linguagem & A33 \\
\hline & & $\begin{array}{l}\text { Educação em saúde, teoria histórico-cultural, significado } \\
\text { dos signos, linguagem }\end{array}$ & A39 \\
\hline & & $\begin{array}{l}\text { Ensino Fundamental, Educação Infantil, teoria histórico- } \\
\text { cultural }\end{array}$ & A45 \\
\hline \multirow{5}{*}{$\begin{array}{l}\text { Ensino de } \\
\text { Química }\end{array}$} & \multirow{5}{*}{12} & $\begin{array}{l}\text { Ensino Fundamental, linguagem, mediação docente, } \\
\text { significação, diálogo formativo }\end{array}$ & A1 \\
\hline & & Mapeamento, teoria histórico-cultural & A2 \\
\hline & & $\begin{array}{l}\text { Uso de tecnologias, mediação, internalização, teoria } \\
\text { histórico-cultural, resolução de problemas }\end{array}$ & A3 \\
\hline & & $\begin{array}{l}\text { Ensino Médio, Pedagogia Histórico-Crítica, experimentação, } \\
\text { materialismo histórico-dialético, mediação, interação } \\
\text { sujeito-objeto, teoria histórico-cultural, instrumentalização }\end{array}$ & \begin{tabular}{|l} 
A4, A28, \\
A31 \\
A37 e A44
\end{tabular} \\
\hline & & $\begin{array}{l}\text { Licenciatura, instrumentalização, teoria histórico-cultural, } \\
\text { mediação, interação }\end{array}$ & $\begin{array}{l}\text { A5, A8, A48 } \\
\text { e A50 }\end{array}$ \\
\hline
\end{tabular}




\begin{tabular}{|c|c|c|c|}
\hline \multirow{3}{*}{$\begin{array}{l}\text { Alfabetização } \\
\text { Científica }\end{array}$} & \multirow{3}{*}{7} & $\begin{array}{l}\text { Teoria histórico-cultural, materialismo histórico-dialético, } \\
\text { fenômeno educacional }\end{array}$ & A10 e $A 24$ \\
\hline & & $\begin{array}{l}\text { Ensino Médio, Pedagogia histórico-crítica, abordagem } \\
\text { contextual }\end{array}$ & $\begin{array}{l}\text { A13, A15 e } \\
\text { A22 }\end{array}$ \\
\hline & & Sequência didática, instrumentalização, mediação & A16 e A23 \\
\hline $\begin{array}{l}\text { Ensino da } \\
\text { Biologia }\end{array}$ & 1 & $\begin{array}{l}\text { Ensino Médio, ressignificação de conceitos, teoria histórico- } \\
\text { cultural, método funcional de dupla estimulação }\end{array}$ & A21 \\
\hline \multirow{3}{*}{$\begin{array}{l}\text { Ensino de } \\
\text { Física }\end{array}$} & \multirow{3}{*}{4} & $\begin{array}{l}\text { Ensino Médio, uso de tecnologias, teoria histórico-cultural, } \\
\text { interação, mediação, contexto sociocultural }\end{array}$ & A11 e A34 \\
\hline & & $\begin{array}{l}\text { Teoria histórico-cultural, interação, funções psicológicas } \\
\text { superiores }\end{array}$ & A27 \\
\hline & & $\begin{array}{l}\text { Licenciatura, teoria histórico-cultural, mediação, } \\
\text { internalização }\end{array}$ & A47 \\
\hline \multirow{2}{*}{$\begin{array}{l}\text { Educação } \\
\text { Ambiental }\end{array}$} & \multirow[t]{2}{*}{4} & $\begin{array}{l}\text { Pedagogia histórico-crítica, materialismo histórico- } \\
\text { dialético, mediação }\end{array}$ & A19 e A30 \\
\hline & & Ensino Médio, mediação, socioambiental & A36 e $A 40$ \\
\hline
\end{tabular}

*Os artigos foram codificados com a letra $A+n=(A 1, A 2 \ldots)$, a fim de preservar a identidade dos autores.

Fonte: Elaborado pelos autores.

Neste trabalho será analisado apenas o foco temático Ensino de Ciências e seus subfocos temáticos. Desse modo o material selecionado será descrito e analisado conforme recomenda Fiorentini (2002), quando aponta os critérios de Kilpatrick (1996, p. 101) "relevância, validade, objetividade, originalidade, rigor e precisão, prognóstico, reprodutibilidade e relacionamento", para descrever e analisar os focos temáticos de um estudo de mapeamento.

Cada foco temático emergiu da leitura dos trabalhos, formando categorias que se diferenciaram umas das outras por suas características específicas, levando-se em conta, principalmente, a nomenclatura utilizada pelos autores na apresentação dos trabalhos. No caso do foco temático Ensino de Ciências, alvo desta pesquisa, foi a categoria que emergiu da leitura dos trabalhos, tendo em vista que os autores adotaram esta denominação como nomenclatura principal do desenvolvimento da pesquisa e abordaram o conjunto de conceitos relacionados com a Química, Física e Biologia.

No caso dos subfocos temáticos o que emergiu da leitura dos trabalhos foram aspectos relacionados ao mesmo nível de ensino, a assuntos com características semeIhantes e principalmente quando da abordagem dos conceitos da teoria histórico-cultural os aspectos que apresentavam convergência conceitual.

\section{CONVERGÊNCIAS E DIVERGÊNCIAS DOS TRABALHOS ANALISADOS}

O foco temático Ensino de Ciências conta com 23 trabalhos e está subdividido em 9 subfocos temáticos de acordo com as convergências relacionadas à THC.

No primeiro subfoco os trabalhos dos autores de A6, A32, A41 e A42 possuem como pontos de convergência a ênfase em seus estudos sobre o Ensino Fundamental e a mediação. Sobre mediação, conceito utilizado nos trabalhos citados, seja diretamente ou indiretamente, Vygotsky et al. (1991, p. 11) "estendeu esse conceito de mediação na interação homem-ambiente pelo uso de instrumentos, ao uso de signos", pois todo aprendizado sofre uma mediação de objetos ou do meio, bem como da linguagem. 
O principal ponto de convergência destes trabalhos é o direcionamento da pesquisa para este nível de ensino e a abordagem de assuntos que sejam relacionados, como participação em exposição com mediação docente, experimentos didáticos em atividades extracurriculares, questão sociocientífica e a mediação docente, e o desenvolvimento do pensamento crítico.

Quanto ao referencial teórico de A6 e A41 foi utilizado o livro $A$ formação social da mente, sendo que no primeiro foi realizada uma discussão sobre os conceitos da teoria histórico-cultural e no segundo há uma única citação de três linhas no corpo do texto, enfraquecendo o trabalho por falta de fundamentação teórica, assim como os autores do A32 não apresentaram fundamentação teórica consistente o suficiente para explicar a relação entre experimento didático e a teoria histórico-cultural, com uma citação de apenas três linhas do livro Pensamento e Linguagem. Por outro lado, em A42 os autores não fazem nenhuma menção a Vygotsky ou à referida teoria.

O segundo subfoco temático está representado nos trabalhos A7, A35 e A49, figurando como principais pontos de convergências as pesquisas realizadas no Ensino Médio, a abordagem de contexto, questões históricas e socioculturais, Pedagogia Histórico-Crítica (PHC), sendo que apenas os autores do primeiro trabalho, $A 7$, fazem alguma menção à teoria histórico-cultural, citando um trecho de duas linhas retirado do livro $A$ Formação social da mente e os outros dois trabalhos não fazem menção a Vygotsky ou a sua teoria.

Os autores do segundo trabalho, A35, apresentam conceitos sobre o pensamento crítico, mas não fazem nenhuma conexão com a THC, assim como os autores do terceiro trabalho, A49, abordam as perspectivas da Pedagogia histórico-crítica aplicada às questões sociocientíficas e à Pedagogia de projetos, porém não há nenhuma menção aos estudos de Vygotsky ou à teoria histórico-cultural.

No terceiro subfoco os autores têm como chamada principal a mediação e a questão sociocultural, destacando-se que o autor do trabalho A9 utiliza textos explicativos como ferramenta de mediação numa abordagem sociocultural. A referência teórica é o livro Pensamento e Linguagem em uma pequena nota de rodapé, ou seja, apesar de apresentar os conceitos de mediação e sociocultural não é realizada uma discussão profunda sobre eles. Em A12 os autores abrem uma discussão muito bem embasada na teoria histórico-cultural à luz dos livros $A$ gênese das funções mentais superiores e Discurso e pensamento, quando são utilizados conceitos de perspectiva sociocultural, linguagem social, internalização de ferramentas culturais e interações sociais, aplicados no Ensino de Ciências.

No trabalho A14 são apresentados alguns pressupostos histórico-culturais, Teoria da Atividade e a atividade de mediação realizada por uma mediadora de uma exposição científica internacional, porém o texto não traz nenhum referencial teórico de Vygotsky, apesar de citar seu nome em alguns momentos. Por outro lado, fica evidente o entendimento dos autores sobre mediação quando na conclusão fazem a seguinte afirmação:

É na dinâmica de superação das contradições que o mediador incorpora novos elementos, cria novos valores e necessidades, o que pode redirecionar sua atividade para os saberes da mediação dos conhecimentos científicos, caracterizando uma atividade de mediação (CERQUEIRA; NEVES; BIZERRA, 2015, p. 8). 
O quarto subfoco relacionado ao foco temático Ensino de Ciências traz como principal característica a realização de mapeamentos nos trabalhos A17, A43, A46 e A51, observando-se que os dois primeiros mapearam trabalhos que relacionam a $\mathrm{PHC}$ ao Ensino de Ciências e identificaram a frágil proposta relacionada a esta teoria, indicando a necessidade de novos estudos a respeito, e quanto à THC os dois trabalhos estabelecem uma relação com a PHC, como é revelado por Souza (2017, p. 3): "Encontramos trabaIhos que utilizaram os fundamentos da PHC, como as obras de Vigotski, referência central da Psicologia Histórico-Cultural, e o Materialismo Histórico-Dialético", mas não foi possível identificar um diálogo aprofundado entre as duas teorias.

Quanto ao trabalho A46 o autor realiza um mapeamento das publicações do $X$ Enpec que tiveram seus referenciais no pensamento crítico no contexto educacional, sem fazer qualquer menção a Vygotsky.

No mapeamento de teses e dissertação que utilizaram os conceitos da THC Bonfin, Solino e Gehlen (2017) constataram que o conceito vygotskyano mais expressivo foi a interação. Em seu mapeamento esses autores observaram que "alguns conceitos que auxiliam na compreensão das ideias de Vygotsky foram pouco explorados, a exemplo das funções psíquicas superiores, internalização e significado" (p. 8). Neste subfoco somente este trabalho tem como referência uma obra de Vygotsky $A$ construção do pensamento e da linguagem.

Os três trabalhos A18, A20 e A38 que compõem o quinto subfoco trazem uma discussão sobre os conceitos espontâneos e científicos à luz da THC, que segundo Vygotsky et al. (1991, p. 86), podem ser explicados da seguinte maneira:

Os conceitos iniciais que foram construídos na criança ao longo de sua vida no contexto de seu ambiente social (Vygotsky chamou esses conceitos de "diários" ou "espontâneos", espontâneos na medida em que são formados independentemente de qualquer processo especialmente voltado para desenvolver seu controle) são agora deslocados para um novo processo, para nova relação especialmente cognitiva com o mundo, e assim nesse processo os conceitos da criança são transformados e sua estrutura muda. Durante o desenvolvimento da consciência na criança o entendimento das bases de um sistema científico de conceitos assume agora a direção do processo.

No trabalho A18 os autores utilizam os conceitos espontâneo e científico para nortear experimentos em sala de aula, buscando uma prática experimental que vá além do espetáculo e da aparência, tendo como referência as obras de Vygotsky Actividad, conciencia y personalidad, A construção do pensamento e linguagem e Psicologia pedagógica, com as quais os autores dialogam no percurso de toda a pesquisa. Os aspectos relacionados aos conceitos espontâneo e científico abordados neste trabalho, à luz das obras elencadas, proporciona ao leitor uma oportunidade de se apropriar deste conhecimento, demonstrando a relação dos conceitos espontâneos com a vida cotidiana e dos conceitos científicos com o ensino sistematizado da escola, articulando a THC com a experimentação na sala de aula (VYGOTSKY, 2009).

Em A20 buscou-se uma interpretação dos mapas conceituais no Ensino de Ciências de acordo com a THC, com a qual os autores dialogaram em praticamente todo o texto à luz das obras Pensamento e linguagem e $A$ construção do pensamento e da 
linguagem de Vygotsky, estabelecendo a relação entre os conceitos espontâneos e científicos com a construção de mapas conceituais para o Ensino de Ciências, evidenciando que os conceitos científicos devem ocupar o topo do mapa por proporcionar maior abstração devido a sua generalidade (VYGOTSKY, 2009).

Quanto ao trabalho de A38 a investigação foi realizada com uma turma de Educação Infantil, utilizando os conceitos espontâneos das crianças sobre flutuar e não flutuar e como elas constroem os conceitos científicos a partir deste marco, utilizando o referencial da THC dos livros Formação Social da Mente e Linguagem, desenvolvimento e aprendizagem. Neste trabalho os autores demonstram claramente a inserção dos conceitos espontâneo e científico em sua pesquisa.

Nos três trabalhos do sexto conjunto de subfocos, A25, A26 e A29, apesar de todas as pesquisas estarem relacionadas ao Ensino Fundamental, o principal ponto de convergência é o uso da tecnologia de acordo com a perspectiva histórico-cultural.

Os autores do estudo A25 trabalharam em sua pesquisa com registros de diálogos, diário de bordo e gravações de áudios, a fim de perceber como é realizada a elaboração conceitual dos assuntos trabalhados que são relacionados à biotecnologia e ao cotidiano. No desenrolar da pesquisa foram explorados conceitos da THC como a internalização, mediação, análise microgenética e funções psicológicas superiores, tendo como referência as obras Formação Social da Mente, Pensamento e Linguagem e Linguagem, desenvolvimento e aprendizagem.

O estudo realizado por A26 teve como objetivo entender a Zona de Desenvolvimento Proximal (ZDP), a qual definiram como "a distância entre o que já sabe (conhecimento real) e o que deverá saber (conhecimento ideal)", na construção do conceito de bacia hidrográfica numa perspectiva sociointeracionista, em consonância com o que explica Vigotsky (2008, p. 98) “A Zona de Desenvolvimento Proximal define aquelas funções que ainda não amadureceram, mas que estão em processo de maturação, funções que amadurecerão, mas que estão presentemente em estado embrionário". A referência utilizada consta nos livros Formação Social da Mente e Pensamento e Linguagem.

Não foi possível identificar a autoria do último trabalho do sexto subfoco, A29, o qual investiga um estudo-piloto sobre a composição de uma sequência didática com o uso de Lousa Digital Interativa (LDI), analisando a interação entre professor e alunos, mediada pela LDI, e qual foi a evolução dos alunos sobre os conceitos estudados. Quanto à referência, mesmo citando Vygotsky em alguns pontos do texto, as citações são bem superficiais e não ocorre uma discussão sobre os conceitos da THC, mesmo tendo como referência os livros Linguagem, desenvolvimento e aprendizagem e Construção do pensamento e da linguagem.

Os três últimos subfocos relacionados ao foco temático Ensino de Ciências constam em três trabalhos diferentes por não ter convergências com os anteriores.

O trabalho A33 levanta a questão da Teoria da Ação Mediada de James Wertsch, aplicada ao uso de jogos como ferramenta cultural que auxilia no desenvolvimento de habilidades relacionadas ao conhecimento científico do Ensino de Ciências, com o objetivo de entender o papel da linguagem nesta interface de apropriação do conhecimento. No corpo do texto Vygotsky é citado apenas para dar suporte para a teoria de James 
Wertsch, autor que dialoga com a THC, e em um breve parágrafo Piaget e Vygotsky são citados sobre o uso de jogos para o desenvolvimento cognitivo, com a referência teórica sendo extraída do livro Formação social da mente.

Quanto ao subfoco ações de educação em saúde sob a perspectiva histórico-cultural, os autores de A39 estabelecem um diálogo com esta teoria, conectando as ideias de Vygotsky e o campo da educação em saúde, reconhecendo "os aspectos sociais, históricos e culturais na determinação dos processos de saúde e doença, dos indivíduos e de suas comunidades" (SANTOS; MEIRELLES, 2017, p. 1). O suporte teórico para as discussões nos trabalhos veio dos livros Formação social da mente e Psicologia pedagógica.

No último subfoco os autores de A45 apresentam uma atividade em que os pesquisadores buscam entender qual é a percepção que alunos da Educação Infantil têm dos seres vivos, mediante uma atividade em que estes têm a oportunidade de fotografá-los na natureza, com os dados sendo interpretados à luz da THC. O trabalho estabelece um diálogo com Vygotsky na introdução e nos resultados da pesquisa, evocando conceitos como construção de conceitos científicos, mediação e internalização, sob a ótica dos livros Formação social da mente, Pensamento e linguagem e Psicologia pedagógica.

Analisando a frequência de categorias no âmbito dos 23 subfocos foi identificado que as categorias teoria histórico-cultural e mediação são encontradas em mais de um subfoco, destacando-se das demais categorias que foram objeto de estudos.

A categoria teoria histórico-cultural foi abordada nos diversos trabalhos em que foram explorados aspectos como a internalização, sentido e significado, significados dos signos, conceitos espontâneos e científicos, planejamento, organização e intencionalidade da atividade educativa. Cabe ressaltar que em artigos como A39 e A45 todo o conjunto da THC foi explorado no sentido de entender a complexidade do ser humano como ser histórico, social, biológico e cultural, em articulação com os temas dos trabalhos.

A segunda categoria que aparece com mais frequência é a mediação, emergindo dos trabalhos analisados a importância do papel do professor como mediador ativo, as interações sociais, as discussões via mediação, as ferramentas culturais de mediação e a importância da mediação na Zona de Desenvolvimento Proximal. Os conceitos de mediação apresentam-se muito bem articulados com os objetivos de alguns trabalhos, como em A14, em que são discutidos os aspectos da mediação em visitas guiadas em uma exposição específica, e no trabalho A29, no qual é analisada a utilização de uma lousa digital como instrumento mediador.

Ao analisar os 23 trabalhos que foram agrupados no foco temático Ensino de Ciências à luz dos objetivos desta pesquisa, foi possível levantar que os livros de Vygotsky mais referenciados foram Formação social da mente (8 trabalhos), Pensamento e Linguagem (6 trabalhos) e Construção do Pensamento e Linguagem (4 trabalhos), ressaltando-se que em alguns os autores se apoiaram em duas ou mais obras. Quanto à discussão da THC, apenas 7 pesquisas abordaram os conceitos com maior profundidade, abrindo o diálogo com a teoria e fazendo citações de suporte ao longo do texto, outras 4 fizeram algumas citações de maneira superficial, 8 pesquisas fizeram citações 
de 3 ou 4 linhas e não discutiram a teoria relacionando-a com o trabalho e 4 pesquisas não fizeram nenhuma citação ou referência à teoria. Isso se deve ao fato de que estas se basearam no pensamento crítico, que não tem raízes diretamente ligadas à THC.

É importante ressaltar que os conceitos de Nível de Desenvolvimento Real, Zona de Desenvolvimento Proximal e Nível de Desenvolvimento Potencial, pontos-chave para o entendimento do processo ensino-aprendizagem à luz da THC, praticamente não foram explorados pelos autores, pois aparece em uma pesquisa apenas, assim como não foram discutidos os conceitos de formação das Funções Psicológicas Superiores, que estão intimamente ligadas ao processo de aprendizagem e desenvolvimento. É possível que a ausência de uma discussão mais aprofundada destes conceitos deva-se ao fato de que a THC ainda carece de um entendimento unificado por parte dos pesquisadores.

\section{CONSIDERAÇÕES FINAIS}

$\mathrm{O}$ total de 51 pesquisas relacionadas à THC, quando comparadas com o total de trabalhos apresentados nos Enpec IX, X e XI representa apenas 1,41\%, porém na última representou $2,02 \%$ e um total de 27 trabalhos, ou seja, mais da metade da soma dos dois eventos anteriores, revelando uma tendência de realização de novos estudos relacionados à área.

Nas discussões sobre a THC cerca de $27 \%$ dos trabalhos conseguiram estabelecer um diálogo efetivo com os conceitos utilizados, com citações específicas e discussão relacionada ao tema da pesquisa; por outro lado, a maioria dos trabalhos abordou de maneira superficial, atendo-se à discussão do trabalho propriamente dito.

Quanto às referências utilizadas nas pesquisas, as obras de Vygotsky mais citadas foram Formação Social da Mente e Pensamento e Linguagem, destacando-se que para estabelecer um diálogo entre a THC e a pesquisas foram utilizados conceitos específicos como "mediação", "linguagem", "internalização", "conceitos espontâneo e específico", "interação", funções psicológicas superiores e sociocultural.

Os estudos relacionados à $\mathrm{PHC}$ somaram um total de 14 trabalhos dos 51 selecionados e foram incluídos nesta pesquisa por terem sua origem no materialismo histórico-dialético e na THC, principalmente quando levantam a necessidade de abordagem do papel dos conceitos científicos na escola.

Na seleção dos trabalhos que comporiam esta pesquisa o descritor "teoria crítica" revelou não estabelecer nenhuma correlação com a THC, pois nenhum dos autores utilizou qualquer referência sobre Vygotsky, assim como o outro descritor "histórico-crítica", relacionado com a Pedagogia Histórico-Crítica, a qual tem seus fundamentos na THC, também não foi suficiente para buscar trabalhos que utilizaram esta teoria como referência.

Mesmo com um esforço enorme por parte dos pesquisadores, buscando relacionar suas pesquisas com a THC, percebe-se que existe certa dificuldade para compor o assunto de pesquisa e a teoria escolhida. Este mapeamento, portanto, poderá ser de grande utilidade para outros pesquisadores do tema, de modo que possam entender os erros e acertos observados e utilizá-los como ponto de partida para seus trabalhos, conforme seu entendimento. 
Por fim cabe ressaltar que este trabalho limitou-se a fazer uma análise dos resumos e uma leitura flutuante de todos os artigos, não se atendo às minúcias de cada um, deixando aberto um enorme leque de opções de trabalhos e análise das pesquisas.

\section{REFERÊNCIAS}

ABRAPEC. Associação Brasileira de Pesquisa em Educação em Ciências. http://abrapecnet.org.br/wordpress/pt/sobreaabrapec/. Acesso em: 20 nov. 2017.

BOGDAN, R. C.; BIKLEN, S. K. Investigação qualitativa em educação. Tradução Maria João Alvarez, Sara Bahia dos Santos e Telmo Mourinho Baptista. Porto: Porto Editora, 1994.

BONFIN, V.; SOLINO, A. P.; GEHLEN, S. T. Vygotsky no contexto da Educação em Ciências: um panorama da produção brasileira. In: Atas do XI Encontro Nacional de Pesquisa em Educação em Ciências, Florianópolis-SC, 2017.

CERQUEIRA, B. R. S.; NEVES, A. L. C.; BIZERRA, A. F. A atividade do mediador em uma exposição científica: um olhar para as contradições. In: ENCONTRO NACIONAL DE PESQUISA EM EDUCAÇÃO EM CIÊNCIAS, 10., 2015, Águas de Lindoia. Atas [...]. Águas de Lindoia, SP: Enpec, 2015.

FIORENTINI, D. Mapeamento e balanço dos trabalhos do GT-19 (Educação Matemática) no período de 1998 a 2001. In: REUNIÃO ANUAL DA ASSOCIAÇÃO NACIONAL DE PÓS-GRADUAÇÃO E PESQUISA EM EDUCAÇÃO - ANPED, 25., 2002. Caxambu, 29 de setembro a 2 de outubro de 2002. Disponível em: http:// www.ufrrj.br/emanped/paginas/conteudo_producoes/docs_25/mapeamento.pdf. Acesso em: 3 nov. 2017.

KILPATRICK, J. Fincando estacas: uma tentativa de demarcar a educação matemática como campo profissional e científico. Zetetiké, Campinas, v. 4, n. 5, p. 99-120, jan./jun. 1996. Disponível em: https://periodicos.sbu.unicamp.br/ojs/index.php/zetetike/article/view/8646867/13768 Acesso em: 27 nov. 2017.

PRODANOV, C. C. Metodologia do trabalho científico [recurso eletrônico]: métodos e técnicas da pesquisa e do trabalho acadêmico. 2. ed. Novo Hamburgo: Feevale, 2013.

REGO, T. C. Vygotsky: uma perspectiva histórico-cultural da educação. 24. ed. Petrópolis, RJ: Vozes, 2013. SANTOS, T. T.; MEIRELLES, R. M. S. Educação em saúde como um processo sociocultural e histórico: diálogos com a teoria de Vygotsky. In: Atas do XI Encontro Nacional de Pesquisa em Educação em Ciências, Florianópolis-SC, 2017.

SOUZA, B. N. O ensino de ciências para a pedagogia histórico-crítica. In: ENCONTRO NACIONAL DE PESQUISA EM EDUCAÇÃO EM CIÊNCIAS, 11., 2017, Flçorianópolis. Atas [...]. Florianópolis, SC: Enpec, 2017.

VYGOTSKY, L. S.; et al. (org.). Trad. José Cipolla Neto, Luis Silveira Menna Barreto, Solange Castro Afeche. 4. ed. brasileira. Formação social da mente. São Paulo, SP: Livraria Martins Fontes Editora, 1991.

VYGOTSKY, Lev Semienovich; LURIA, Alexander Romanovich; LEONTIEV, Alex N. Trad. Maria da Pena Villalobos. Linguagem, desenvolvimento e aprendizagem. 15. ed. São Paulo: Ícone, 2017.

VYGOTSKY, Lev Semienovich. Trad. Paulo Bezerra. A construção do pensamento e da linguagem. 2. ed. São Paulo: Martins Fontes, 2009.

VYGOTSKY, Lev Semienovich. Trad. Jefferson Luiz Camargo. Pensamento e linguagem. 4. ed. São Paulo: Martins Fontes, 2008.

VYGOTSKY, Lev Semienovich. Psicologia pedagógica. 3. ed. São Paulo: Editora Martins Fontes, 2010. 